\title{
Can Umbilical Cord Mesenchymal Stem Cells Treatment Be a Hope for Patients with Refractory Crohn's Disease?
}

\author{
Younjoo Kim \\ Division of Gastroenterology, Department of Internal Medicine, Korea Cancer Center Hospital, Korea Institute of Radiological and Medical \\ Sciences, Seoul, Korea
}

See “Umbilical Cord Mesenchymal Stem Cell Treatment for Crohn's Disease: A Randomized Controlled Clinical Trial” by Jian Zhang, et al. on page 73, Vol. 12. No. 1, 2018

Inflammatory bowel disease (IBD) is a disease where an inappropriate inflammatory response occurs because of impaired tolerance of the immune system to intraluminal substances in a genetically susceptible host. ${ }^{1}$ Many drugs, such as steroid, 5-aminosalicylic acid, and immune modulators, have been used in patients with IBD, and the introduction of anti-tumor necrosis factor (anti-TNF) agents has led to a dramatic improvement in treatment response in patients with severe IBD. ${ }^{2}$ Despite the best medical and surgical treatment, a significant proportion of patients with IBD continue to suffer. Stem cell therapies, including hematopoietic stem cell transplantation (HSCT) and mesenchymal stem/stromal cell (MSC) treatment, are carefully being implemented in select patients who have failed conventional treatment.

HSCT has been carefully attempted in patients with severe Crohn's disease (CD) who are refractory to conventional therapy after case reports in the late 1990s indicated complete remission of CD post HSCT in patients with both hematological malignancy and severe CD. ${ }^{3}$ HSCT theoretically resets the background of the host adaptive immune response, including the imbalance between Thelper (Th)1/Th17 cells and regulatory T lymphocytes (Treg). Most patients with CD who undergo HSCT experience recurrence; however, the relapse is mild and can be treated. ${ }^{3}$ Therefore, HSCT could be an alternative for patients with refractory severe CD. However, HSCT has major disadvantages, as it requires myeloablative or nonmyeloablative conditioning, and is still limited to being as a standard treatment for CD.

MSCs are pluripotent progenitor cells that can differentiate into various cells, such as osteoblasts, adipocytes, and chondro- blasts, and can be isolated from the bone marrow (BM), umbilical cord (UC), adipose tissue, and other connective tissues of most organs. ${ }^{4}$ In addition to this plasticity, it has been shown that MSCs have powerful immunomodulatory effects and they are useful for the treatment of several autoimmune diseases, including CD. ${ }^{4}$ MSCs inhibit the differentiation of monocytes to dendrite cells; proliferation B lymphocytes and the subsequent production of immunoglobulin; and the proliferation and activation of Th1, Th2, and Th17 lymphocytes, and natural killer cells. $^{3-5}$ Moreover, MSCs can promote the differentiation of regulatory $\mathrm{T}$ cells. These effects are caused by direct cell-to-cell contact and secreted cytokines, such as transforming growth factor $\beta$, interleukin-6, interleukin-10, prostaglandin E2 and hepatocyte growth factor. ${ }^{4,5}$ MSCs also have immune-privilege potential because they do not express human leukocyte antigen (HLA) class II nor co-stimulatory molecules (CD80, CD86, or CD40). ${ }^{4}$ Therefore, unlike HSCT, MSC treatment do not require HLA matching or cytotoxic chemotherapy before treatment; have no fatal side-effects, such as immune rejection, associated with it; and can standardize cell therapy through commercialization.

In the current issue of Gut and Liver, a prospective open label trial performed by Zhang et al. ${ }^{6}$ aimed to investigate the efficacy and safety of systemic infusion of MSCs from UC (UC-MSC) in patients with steroid dependent CD. In this study, 82 patients with steroid dependent CD were randomized, and 42 patients who were assigned to the MSC infusion group received UCMSCs via peripheral intravenous infusion of $1 \times 10^{6}$ cells $/ \mathrm{kg}$ once a week, for 4 weeks. At 12 months after treatment, the Crohn's

Correspondence to: Younjoo Kim

Division of Gastroenterology, Department of Internal Medicine, Korea Cancer Center Hospital, Korea Institute of Radiological and Medical Sciences,

75 Nowon-ro, Nowon-gu, Seoul 01812, Korea

Tel: +82-2-970-1208, Fax: +82-2-970-2438, E-mail: younjoo282@kirams.re.kr

pISSN 1976-2283 eISSN 2005-1212 https://doi.org/10.5009/gnl17492

(a) This is an Open Access article distributed under the terms of the Creative Commons Attribution Non-Commercial License (http://creativecommons.org/licenses/by-nc/4.0) which permits unrestricted non-commercial use, distribution, and reproduction in any medium, provided the original work is properly cited. 
disease activity index (CDAI), Harvey-Bradshaw index, and corticosteroid requirement had decreased by $62.5 \pm 23.2,3.4 \pm 1.2$, and $4.2 \pm 0.84 \mathrm{mg} /$ day, respectively, in the UC-MSC group, while they decreased by $23.6 \pm 12.4,1.2 \pm 0.58$, and $1.2 \pm 0.35 \mathrm{mg} /$ day, respectively, in the control group $(\mathrm{p}<0.01, \mathrm{p}<0.05$, and $\mathrm{p}<0.05$, UC-MSC vs control, respectively). No serious adverse events were observed, as only four patients experienced fever after cell infusion. There are only a few studies regarding systemic infusion of MSCs in patients with CD. Duijvestein et al. ${ }^{7}$ showed that autologous BM-MSCs alleviated the condition of patients with $\mathrm{CD}$, with mild adverse effects. In the study by Forbes et al., ${ }^{8}$ allogeneic BM-MSCs were infused four times, achieving favorable improvements of CDAI with only one serious adverse event, probably not caused by MSCs.

Currently, MSCs are mainly clinically isolated from the BM, adipose tissue, and UC; however, it is still unclear which source of MSCs is most beneficial in terms of immunomodulation. In the clinical aspect, however, the advantage of UC-MSCs is the absence of additional invasive steps to obtain MSCs because they use donated UC. Mayer et al. ${ }^{9}$ reported that UC-MSCs appeared to be safe and well-tolerated in subjects with treatmentresistant CD in their Phase I trial. All six subjects who received two infusions of $2 \times 10^{8}$ cells (low dose) achieved a clinical response. In six patients in the high dose group (two infusions of $8 \times 10^{8}$ cells), two patients achieved response because of more severe disease activity. The most adverse events were mild to moderate in severity, and included headache, nausea, fever, and infusion site reactions. ${ }^{9}$

There are some limitations and concerns in this study. Although the authors suggested that UC-MSC treatment improved the patients' clinical manifestations, most patients, however, still received the steroid treatment after 12 months. This means this stem cell therapy does not solely work compared with other therapies like anti-TNF agents. In addition, they did not confirm histological improvement of the inflamed lamina propria to show direct evidence of MSC's action.

Another issue is safety. The safety of MSC is generally acceptable. ${ }^{10}$ In a meta-analysis of 36 trials and 1,087 patients, only transient fever was associated with MSC administration. There were no direct associations between MSC infusion and the development of acute infused toxicity, organ system complications, infection, death or malignancy. ${ }^{3,10}$ However, since MSC infusion is still an experimental treatment, there is no standard protocol for isolation and preparation of MSC, optimal infusion cell dose, and injection frequency. Additionally, the authors did not monitor HLA antibodies to check potential immunogenicity by UC-MSC. Therefore, the concerns about patient safety are not completely resolved.

Regardless of this limitation, this study provides useful information about systemic MSC infusion in patients with refractory CD. Therefore, the standard protocol for systemic infusion of MSCs and large-scale prospective studies are needed to determine the role of UC-MSC in patients with refractory CD.

\section{CONFLICTS OF INTEREST}

No potential conflict of interest relevant to this article was reported.

\section{REFERENCES}

1. Knights D, Lassen KG, Xavier RJ. Advances in inflammatory bowel disease pathogenesis: linking host genetics and the microbiome. Gut 2013;62:1505-1510.

2. Park JJ, Yang SK, Ye BD, et al. Second Korean guidelines for the management of Crohn's disease. Intest Res 2017;15:38-67.

3. Hawkey CJ, Hommes DW. Is stem cell therapy ready for prime time in treatment of inflammatory bowel diseases? Gastroenterology 2017;152:389-397.e2.

4. Gao F, Chiu SM, Motan DA, et al. Mesenchymal stem cells and immunomodulation: current status and future prospects. Cell Death Dis 2016;7:e2062.

5. Grégoire C, Lechanteur C, Briquet A, et al. Review article: mesenchymal stromal cell therapy for inflammatory bowel diseases. Aliment Pharmacol Ther 2017;45:205-221.

6. Zhang J, Lv S, Liu X, Song B, Shi L. Umbilical cord mesenchymal stem cell treatment for Crohn's disease: a randomized controlled clinical trial. Gut Liver 2018;12:73-78.

7. Duijvestein M, Vos AC, Roelofs H, et al. Autologous bone marrowderived mesenchymal stromal cell treatment for refractory luminal Crohn's disease: results of a phase I study. Gut 2010;59:16621669.

8. Forbes GM, Sturm MJ, Leong RW, et al. A phase 2 study of allogeneic mesenchymal stromal cells for luminal Crohn's disease refractory to biologic therapy. Clin Gastroenterol Hepatol 2014;12:6471.

9. Mayer L, Pandak WM, Melmed GY, et al. Safety and tolerability of human placenta-derived cells (PDA001) in treatment-resistant crohn's disease: a phase 1 study. Inflamm Bowel Dis 2013;19:754760.

10. Lalu MM, McIntyre L, Pugliese C, et al. Safety of cell therapy with mesenchymal stromal cells (SafeCell): a systematic review and meta-analysis of clinical trials. PLoS One 2012;7:e47559. 